\title{
UNA LIBERALIDAD EN LA PUEBLA DE HÍJAR (TERUEL) Y LA LOCALIZACIÓN DEL MUNICIPIVM OSICERDA
}

\author{
POR \\ FRANCISCO BELTRÁN LLORIS \\ Universidad de Zaragoza
}

\section{RESUMEN}

El reciente hallazgo en La Puebla de Híjar (Bajo Aragón turolense) de un epígrafe fragmentario relativo a un acto de munificencia en el que se menciona la ciuitas hasta ahora ilocalizada de Osicerda permite identificar este municipio en la localidad turolense o en sus alrededores, al tiempo que documenta un tipo de liberalidad infrecuente en el norte de Hispania.

\section{SUMMARY}

The recent discovery of a fragmentary inscription refering to Osicerda in La Puebla de Hijar (Bajo Aragón, Teruel) makes possible to fix here - or in the surrounding territory - the situation of this municipium. The inscription contains also a reference to an act of munificence quite inusual in the north of Hispania.

Pese a su estado fragmentario, el reciente hallazgo de una inscripción en La Puebla de Híjar ${ }^{1}$, localidad del bajo Aragón turolense asentada en el valle del río Martín, a una decena de kilómetros al sur del Ebro, permite colmar en parte el vacío informativo que a propósito de las comunidades urbanas romanas padecía esta comarca y Teruel en su conjunto - se trata de la primera ciuitas identificada en la provincia-, pues autoriza a ubicar en la zona el hasta ahora elusivo municipio de Osicerda, al tiempo que documenta un acto de munificencia cívica poco habitual en la epigrafía del norte de Hispania.

1. Tuve conocimiento de la pieza a comienzos de 1996 gracias a la amabilidad de $\mathrm{D}^{\mathrm{a}}$ Luisa Gimeno que me mostró una fotografía de la misma en cuyo final se apreciaba con toda claridad el nombre amputado de Osicerda, aunque sin poder establecer si se trataba de una mención de origo - que no habría sido de gran auxilio para la localización del municipio- o de otro tipo de referencia que permitiera precisar la ubicación de la ciudad.

\footnotetext{
${ }^{1}$ Véase la noticia de su descubrimiento en L. y C. Gimeno, «Una nueva inscripción de La Puebla de Híjar (Teruel)», Kalathos, en prensa.
}

In situ pudimos comprobar que se trataba del fragmento inferior central de una losa de caliza de (34.5) x (45) $\times 14 \mathrm{~cm}$ con marco moldurado conservado en la parte inferior y letras de $6 \mathrm{~cm}$ de altura en la $1.1^{\mathrm{a}}$, de 4.2 en la $1.2^{\mathrm{a}}$ y de 4.5 en la $1.3^{\mathrm{a}}$, e interpunción triangular. Fue hallado durante el verano de 1995 al desmontar el muro del patio de una casa sita en la c/ Nueva núm. 74 de La Puebla de Híjar, propiedad adquirida pocos años atrás por D. Dionisio Pérez Abad, en donde se conserva y pude examinarla el 3 de febrero de 1996 en compañía de L. Gimeno y F. Marco (fig. 1):

$$
\begin{aligned}
& {[---]+\cdot \text { Sergia } N[---]} \\
& [---] O \cdot \text { sua•pecun[ia --- }] \\
& {[--- \text { in]çolìs•Osicer[densibus ---] }}
\end{aligned}
$$

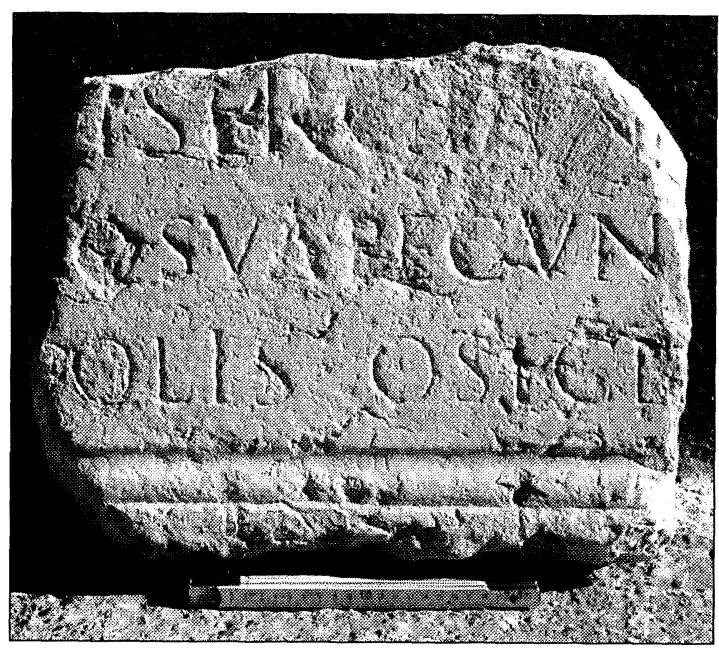

Fig. 1.-Inscripción de La Puebla de Híjar.

L. 1: de la primera letra sólo se conserva la parte inferior de un ástil recto.

L. 3: la parte superior de la $\mathrm{C}$ se observa con claridad en la piedra; la primera I, longa; la lectura más probable de la cuarta letra de la segunda palabra es C, si bien no puede excluirse por completo la posibilidad de leer G. 
El texto conservado hace referencia a una liberalidad sufragada a sus expensas, sua•pecun[ia ---], por una persona, quizás la Sergia $\cdot \mathrm{N}[---]$ mencionada en $1.1^{a}$ con letras de mayor tamaño ${ }^{2}$, entre cuyos beneficiarios se contaban los incolae de Osicerda, única forma en la que puede entenderse [---]çolìs•Osicer[---], pues, por un lado, no parece haber otra restitución más satisfactoria para el segmento [---]çolìs que con toda seguridad se lee sobre la piedra (fig. 2) ${ }^{3}$, mientras que, por otro, la palabra Osicer[densibus], aun parcialmente conservada, debe referirse al municipio de derecho latino atestiguado por diversos conductos y mencionado por Plinio entre las ciuitates de Latini ueteres del convento cesaraugustano (NH III 24).

Respecto a este último vocablo no quisiera dejar de apuntar una duda de lectura que afecta a la cuarta letra, transcrita como $\mathrm{C}$, pero de cuyo extremo inferior surge un pequeño, pero nítido, trazo vertical (fig. 3), mucho más breve que el de la $G$ de Sergia, en la $1.1^{\text {a }}$-cuyas letras son $1.5 \mathrm{~cm}$ mayores que las de la $3^{\text {a }}$-, pero claro si se compara con la $\mathrm{C}$ de pecun[ia], en la línea $2^{\mathrm{a}}$ (fig. 4). Aunque la

\footnotetext{
${ }^{2}$ Las razones que inducen a entender Sergia como nomen y no como tribus son de diversa índole. En primer lugar, la adscripción tribal suele consignarse de forma abreviada - Serg., Ser. - y no desarrollada, según puede comprobarse en los epígrafes peninsulares relativos a hispanos inscritos en la Sergia (la única posible excepción está constituida por la anómala inscripción de Tarraco editada por M. Mayer, cf. HEp 3, 1993, 368: domo Sergi[a] / Scallabi). Por otro lado, la tribu de Osicerda parece ser la Galeria, a juzgar por la dedicatoria CIL II $4267=$ G. Alföldy, Die römischen Inschriften von Tarraco, Berlin 1975 (= RIT), núm. 341, lám. 40, $(\mathrm{L} \cdot$ Cornelio | $\bullet \bullet \cdot G a l \mid$ Romano | flamini $\bullet \Pi$ uir | Osicerd $\bullet$ et | P uir coloniae I Tarraconens...), en concordancia con la fecha augustea en la que parece haber sido privilegiada la ciudad. Es cierto que, en algunas comunidades, coexistían la Galeria y la Sergia como tribus cívicas, pero se trata de ciudades con perfiles muy distintos a los de Osicerda, todas de rango colonial con la sola excepción de Italica -municipio hasta el reinado de Adriano- y, a menudo, de fundación muy antigua: Corduba, Hasta, Hispalis, Italica, Tucci y Vrso en la Bética; Norba y Scallabis en Lusitania; y Carthago noua y Salaria en la Tarraconense (cf. R. Wiegels, Die Tribusinschriften des römischen Hispaniens, Berlin, 1985, 167-168 y también s. v. Osicerda; además, J. González, «Vrso ¿tribu Sergia o Galeria?», en J. González, ed., Estudios sobre Vrso, Sevilla, 1989, 133-153). Por el contrario, la presencia de Sergii en diversos puntos de la región refuerza la identificación de Sergia como nomen en el epígrafe de La Puebla de Híjar: Osca (CIL II 3002: L. Sergius Quintillus, sevir), Sofuentes, Zaragoza (CIL 2975: Sergia Praesentina; AE 1977 477: Sergius [--- ]) y La Puebla de Valverde, Teruel (P. Atrián, «Actividades del Servicio arqueológico provincial en 1970», Boletín Informativo de la Diputación de Teruel 21, 1971, 38: Sergia Seuera).

${ }^{3}$ En una inscripción de esta índole no hay ninguna otra solución preferible para ese final: cf. O. Gradenwitz, Later culi uocum Latinarum, Leipzig, 1904 (Hildesheim, 1966), 293-294 (-cola) y 500 (-colus).
}

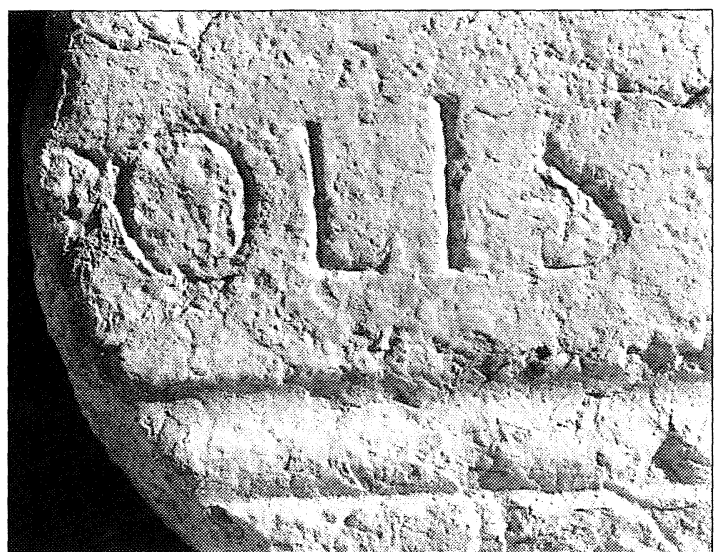

Fig. 2.-Detalle del comienzo de la última línea.

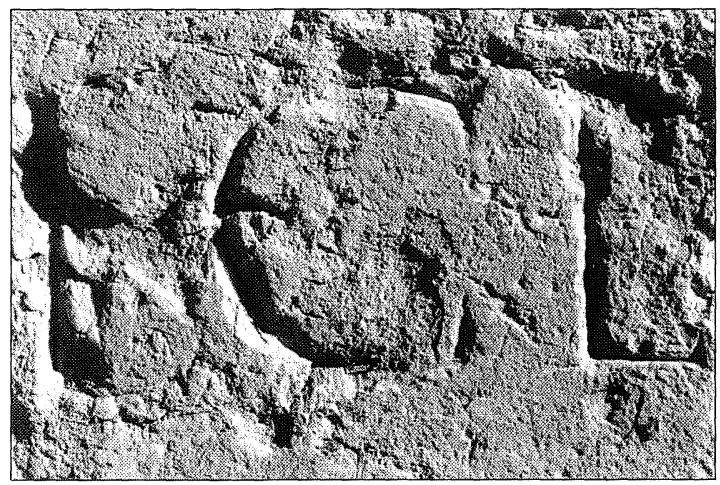

Fig. 3.-Detalle de la C de Osicer[densibus].

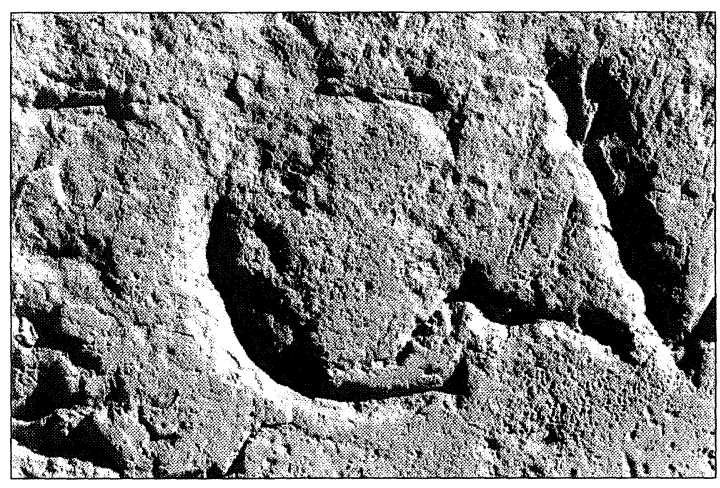

Fig. 4.-Detalle de la C de pecun[ia]

lectura más probable sea Osicer[densibus ---], antes de descartar por completo la alternativa Osiger[densibus ---] debe recordarse que la tradición pliniana, aun constituyendo un testimonio secundario y sometido a los avatares de la transmisión 
textual, ofrece en todos los manuscritos conservados la lección unánime Ossigerdenses ${ }^{4}$.

${ }^{4}$ Así D. Detlefsen, Die geographischen Bücher (II, $242-$ VI Schluß) der Naturalis historia des C. Plinius Secundus, Berlin, 1904 ad III 24. Broterius en su edición de 1779 sugirió la enmienda Osicerdenses, basada en Ptolomeo (II 6, 62:

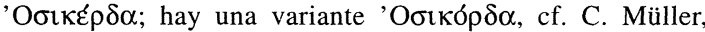
Claudii Ptolemaei Geographia, Parisiis, 1883, 186), que C. Mayhoff incoporó a su edición teubneriana (C. Plini Secundi Naturalis historiae libri XXXVII, vol. 1, Lipsiae, 1906) y, desde entonces, se ha consolidado en la presentación del texto. La versión indígena del topónimo es usekerte, según recogen tanto las leyendas monetales (A. Vives, La moneda hispánica, Madrid, 1924-1926, lám. 72; L. Villaronga, Corpus nummum Hispaniae ante Augusti aetatem, Madrid, 1994, 184) cuanto el epígrafe musivo ibérico de Caminreal (usekerteku; J. Untermann, Monumenta linguarum Hispanicarum $=$ MLH, II.2, Wiesbaden, 1990, E.7.1.), lo que no resuelve el problema, pues, como es sabido, la escritura paleohispánica no disponía de signos diferentes para distinguir las oclusivas sonoras de las sordas y en cualquier caso ello no asegura la forma en la que los romanos transcribieran el topónimo. Tampoco es definitivo el testimonio de las dos inscripciones de Tarragona que se refieren a Osicerdenses, una conservada y perdida la otra, ya que aunque en la primera la lectura Osicerd es clara (CIL II $4267=$ RIT 341, lám. $40,1)$-de la segunda se conserva una tradición insegura que, sin embargo, no afecta excesivamente a la grafía del gentilicio (CIL II 4241 = RIT 325) - , debe tenerse en cuenta que no es infrecuente que las inscripciones de la capital provincial recojan una grafía incorrecta del nombre de una ciudad o, cuando menos, divergente respecto de la comprobada en los epígrafes locales o en otras fuentes, según queda bien ilustrado, por ejemplo, con el caso de Pompelo (Pamplona; expresado en la forma Pompaelo en varias inscripciones de Tarragona -CIL II 4208, 4234, 4246; también en CIL XVIII 414 de Dax-, pero que figura como Pompe[l]onensis, Pompe[l]. y Pompelonensis en tres epígrafes procedentes de las cercanías de Pamplona, redactados por lo tanto en la propia ciuitas - CIL II 2958; 2959; 2960-, forma idéntica a la de los códices plinianos, a la de las fuentes viarias - It. Ant. 455, 5 y Rav. 316, 4: Pompelone- y que alterna con $\Pi$ $\mu \pi \alpha \iota \lambda \omega v$ en los códices estrabonianos -también По $\mu \pi \varepsilon \dot{\varepsilon} \lambda \omega \mathrm{v}$, По $\mu \pi \varepsilon \lambda \omega \nu$, По $\mu \pi \varepsilon \lambda \omega \mathrm{v}-)$. Tampoco faltan alternancias en la epigrafía de una misma ciudad, como recientemente ilustra el caso de Labitolosa (La Puebla de Castro, Huesca: Cf. ciues Labitolosani et incolae-CIL II 5837-, pero Genio municipi Labitulosani en P. Sillières, M. A. Magallón y M. Navarro, «El municipium Labitulosanum y sus notables: novedades arqueológicas y epigráficas», AEspA 68, 1995, 118-119 y 126-127). Fuera de los testimonios mencionados sólo restan las monedas que no he tenido oportunidad de examinar directamente: aparte de las bilingües, que no afectan al caso, pues recogen el nombre de la ciudad abreviado (OSI), las más relevantes son las acuñadas bajo el principado de Tiberio con la leyenda habitualmente transcrita MVN. OSICERDA (P. P. Ripollés en A. Burnett, M. Amandry y P. P. Ripollès, Roman Provincial Coinage. I, London y Paris, 1992, 142; Vives 1924, cit. más arriba, IV, 101), cuya inspección a través de fotografías no me ha permitido despejar todas las dudas: en el caso de los ejemplares que reproduce Vives (1924, cit. más arriba, lám. 159), la leyenda del as parece OSICERDA (lám. 159, 1), a cambio la del cuadrante podría entenderse OSIG. En el caso del catálogo de X. y F. Calicó (Catálogo de monedas antiguas de Hispania, Barcelona, 1979, 174), el semis núm. 1254 dice con claridad OSIC, pero a cambio la grafía del as núm. 1252 es de nuevo dudosa, al igual que ocurre con la del núm. 468 de Ripollès (1992, cit. más arriba).
La presencia del marco moldurado rodeando la inscripción aconseja una datación en el último tercio del siglo I d. E. o, mejor, en el siglo II, período del que data la mayor parte de las acciones de munificencia cívica conocidas en Hispania ${ }^{5}$.

2. En lo que respecta al texto perdido, cuando menos cabe proponer un suplemento bastante seguro ante [in]çolis y realizar algunas reflexiones acerca de la naturaleza del acto que reflejaría el epígrafe.

A propósito del primero, es más que probable que el epígrafe incluyera ante los incolae una referencia a los ciudadanos del municipio, pues aquéllos siempre figuran asociados a éstos cuando comparecen en las inscripciones como sector constitutivo del populus, ya sea protagonizando una iniciativa, ya sea beneficiándose de ella ${ }^{6}$. Tal vinculación re-

${ }^{5}$ Sobre este hecho, varias veces destacado, véase últimamente, P. Le Roux, «Epigrafia ed evergetismo: la Spagna nel II-III secolo d. C.», en Epigrafia e territorio. Politica e società. Temi di antichità romane III, Bari, 1994, 175.

${ }^{6}$ Para Hispania cf. CIL II Supp. p. 1160. Como protagonistas de una iniciativa cívica aparecen, por ejemplo, en: CIL II 2044 (Anticaria): ciues et incolae junto a los decuriones; CIL II 3251-2 (Baesucci): ciues Baesuc. et incolae; CIL II 2022 (Singili): ciues Singilienses et incolae; CIL II 2025 (Singili): ciues et incolae m. m. Flauii Lib. Sing.; HEp 2, 1990, 462-3 y 469 (Singili): ciues et incolae [mun.] Liberi Sing.; CIL II 3419 (Carthago noua): coloni et incol[ae] I libertini; CIL 5837 (Labitolosa): ciues Labitolosani et incolae. Como beneficiarios son mencionados en: Lex Vrsonensis, $§ 126$, a propósito de los ludi scaenici que debían sufragar los magistrados con la obligación de suministrar asientos a los colonos Gene[t]iuos incolasque hospites atuentoresque; en CIL II 1276 (Siarum) Dulcinia Mes[---] instituye una fundación para repartir, mientras viva, tres denarios a los decuriones, dos a los seviros y uno plebei utriusque sexus et incolis; también en la sportula atestiguada en CIL II 1282 (Salpensa, 147 d. E.) el reparto afecta a plebeis singulis incolis uiris । et mulieribus intra muros | habitantibus praestantibus; en CIL II 5489 (Murgi) el sevir L. Emilio Dafno regala a los municipes unas termas y, además, ciuibus et incolis epulum dedit junto con una sportula de un denario por persona; en HAEp 1955-1956, 1027 (Naeua) el dunviro L. Elio Eliano ofrece un epulum municip. et incolis utriusque sexus con motivo de la dedicación de unas estatuas, acción que parece ser la consignada también en el epígrafe fragmentario CIL II 1191 (cf. del Hoyo en HEp 3, 1993, 336); en CIL II 2011 (Nescania) Fabia Restituta respondió a la decisión del ordo de la ciudad de erigir una estatua a su hijo con la asunción de los costes (impensam remisit), la celebración de un epulum para los decuriones y sus hijos, una distribución de dos denarios ciuibus atque incolis, y de uno seruis stationariis con motivo de la dedicatio; en CIL II 2100 (Iliturgi) Sex. Quintio Fortunato celebra su obtención del sevirato con un epulum para ciuibus et incolis y circenses; en HEP 2, 1990, 469 (Singili, 109 d. E.) M. Valerio Proculino, dunvir, agradeció con gran generosidad la erección de una estatua y la concesión de otros especialísimos honores organizando ludi publici y priuati, y, además, item populum uniuersum in municipio $\mid$ habitantem et incolas oleo et balineo I gratuito dato peruocauit, y gymnasium 
sulta comprensible dada la posición marginal que los extranjeros domiciliados jugaban en la vida pública de la ciudad, bien ilustrada en Hispania por la ley flavia municipal que sólo les concedía un pequeño espacio político en la comunidad ${ }^{7}$; por ello, sus comparecencias en las inscripciones tienen lugar en asociación con el cuerpo cívico en las contadas ocasiones documentadas, a juzgar por las cuales la restitución más probable del texto en el caso que nos ocupa sería [ciuibus et in]çolis ${ }^{8}$.

La mención de los incolae, además de ser un hecho infrecuente en la epigrafía de la Hispania citerior -máxime como beneficiarios de una libera-

et balinea uiris et mulieribus gratuita praestitit. Aunque con frecuencia el gentilicio o la referencia a la ciuitas suele aparecer tras los ciudadanos y antes de los incolae (CIL II 2022, $3251-2,5837$, Vrs. $\$ 126$ ), en otros casos - como ocurriría en nuestra inscripción- figura al final, tras los incolae: así en los citados HEp 2, 1990, 462-3 y 469; ver, además: CIL II 1041 (Monesterio: municipes et incolae pagi Tran[s]lucani et pagi Suburbani), ILS 3752 (Asisium: municipibus et incolis Asisinatibus), 4907 (Salonae: decurionibus, colonis, incolis coloniae Martia[e] Iuliae Salonae), 6641 (Tuficum: municipes et incol. Tuf. utriusque sexus).

${ }^{7}$ Los incolae estaban asimilados a los ciudadanos en las cargas (cf. Irn. \& 83, De munitione), pero carecían de plenos derechos cívicos y pesaban poco políticamente al votar concentrados en una sola curia (cf. Mal. $\$ 53$, In qua curia incolae suffragia ferant). Naturalmente había casos específicos de promoción personal como el del incola de Axati (Lora del Río) que llegó a ser decurión (CIL II 1055). Sobre la condición jurídica de los incolae, v. entre otros trabajos: A. D'Ors, Epigrafía jurídica de la España romana, Madrid, 1953, 151 ss., 207, 228, 315, etc.; R. Portillo, Incolae, Córdoba, 1983; F. J. Lomas, «De la condición social de los incolae con especial referencia a Hispania», Habis 1819, 1987-8, 383-396. Sobre el papel de los incolae en relación con las liberalidades, J. F. Rodríguez Neila, «Liberalidades públicas y vida municipal en la Hispania romana», Veleia 6, 1989, 169.

${ }^{8}$ De las diferentes formas en las que el conjunto de ciudadanos podía ser denominada (populus, plebs, municipes, ciues), la forma predominante en Hispania es ciues, cf. CIL II Suppl. p. 1160. Véase, por ejemplo, el significativo caso de Murgi (Dalias, Almería) en el que el sevir L. Emilio Dafno thermas I sua omni impensa municipibus Murg. I dedit, pero $X$ sin|[g]ulos ciuibus et incolis epulum dedit (CIL II 5489). A cambio en Italia y otras zonas del Imperio predomina la expresión municipibus et incolis, cf. ILS 2666 (Tuficum), 2637 (c. Tibur), 3752 (Asisium), 5671 (Interamnia), 5673 (Suasa), etc., que es también la habitual en la Ley Flavia municipal ( $\$ 83$ : «quicumque municipes incolaeue eius municipi erunt»; $\S 94$ : «Huic legi uti municipes parere debuirint, ita eius municipii incolae parento») y comparece igualmente en HAEp 1955-1956, 1027 (epulo munic. et incolis utriusque sexus dato) y en CIL II 1041 (municipes et incolae pagi Tran[s]lucani et pagi Suburbani). Al respecto de Italia, véase $\mathrm{S}$. Mrozek, «Les béneficiaires des distributions privées d'argent et de nourriture dans les villes italiennes à l'époque de Haut-Empire», Epigraphica 34, 1972 (30-54), 42 ss., en cuya opinión, bien fundamentada, las expresiones populus y plebs comprendían a todos los habitantes varones libres de la comunidad, incluidos los incolae, mientras que los términos municipes y coloni, los excluían. lidad ${ }^{9}$ - , permite una aproximación a la naturaleza de la munificencia de la que disfrutaron. Su mención no tendría sentido en el caso de que ésta afectara sin más al conjunto de la comunidad ${ }^{10}$, por lo que la medida en cuestión debió de ser de índole selectiva y personal: una distribución de dinero ${ }^{11}$, alimentos ${ }^{12} \mathrm{o}$ aceite para uso corporal ${ }^{13}$, la celebración de un banquete ${ }^{14} \mathrm{o}$ el ofrecimiento de acceso

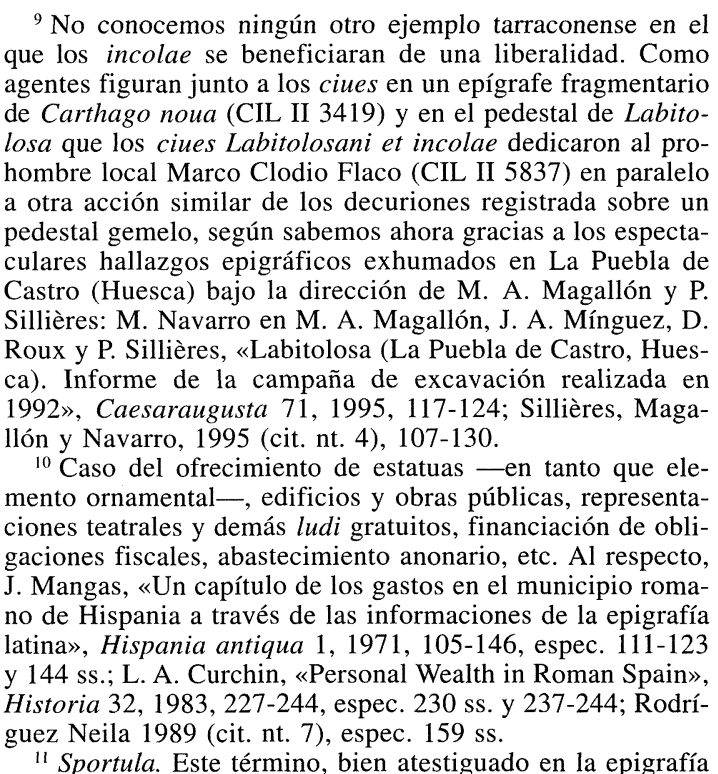
hispana (cf. CIL II Supp. p. 1194; E. Melchor Gil, El mecenazgo cívico en la Bética. La contribución de los evergetas a la vida municipal, Córdoba, 1994, 121 ss.), no aparece fuera de Roma hasta el siglo II d. E. como ya señalara $S$. Mrozek, «Quelques remarques sur les inscriptions relatives aux distributions privées d'argent et de nourriture dans les municipes italiens aux I, II et III $^{\mathrm{e}}$ siècles d. n. e», Epigraphica 30, 1968, 167.

${ }_{12}$ Las inscripciones italianas registran sobre todo repartos de mulsum et crustulum o panis et uinum, así como uiscerationes, que, por el contrario, no se documentan en Hispania, en donde predominan la celebración de banquetes o la distribución de dinero. De cualquier forma, todas estas liberalidades persiguen una finalidad semejante $\mathrm{y}$, en Italia, parecen sucederse en algunos casos, por ejemplo el reparto de crustulum y mulsum es más frecuente en el siglo I, mientras que en el II se hacen más raros los repartos de viandas y aumentan las celebraciones de cenae o los repartos de dinero; cf. Mrozek 1968 (cit. nt. 11), 169.

${ }^{13}$ Éste suele ser denominado oleum, gymnasium -formas ambas atestiguadas un par de veces en la Bética en relación con el acceso gratuito a las termas - o balineum; Melchor 1994 (cit. nt. 11), 127: HEp 2, 1990, 469 (Singili Barba); HAEp 1-3, 1950-1952, 166 (Lucurgentum).

${ }^{14}$ De los diversos términos atestiguados epigráficamente -epulum, conuiuium, cena, prandium-, el más habitual en Hispania es epulum (CIL II Supp. p. 1194; Melchor 1994, cit. nt. 11, 120-121); cena figura en varias ocasiones: CIL II 1046 (Iporca), 1278 (Salpensa), 1721 (Sosontigi), 2156 (Epora) así como en la ley Vrsonense que también emplea el término conuiuium. Prandium no está documentado. Sobre los epula en la Bética puede verse J. del Hoyo, «Un aspec- 
gratuito a las termas, por citar los tipos de donaciones más frecuentes en la epigrafía del Principado, bien comprobadas en las inscripciones de la parte meridional de la Península, aunque raras en las del norte de Hispania ${ }^{15}$. Estas acciones, como es bien sabido, estaban asociadas a una variada gama de celebraciones políticas o familiares como la obtención de una magistratura o del sevirato, el nombramiento como patrono o la recepción de otro honor decretado por la ciudad, la dedicatio de estatuas o edificios, la conmemoración de un difunto, del dies natalis o de algún aniversario, o, incluso, con motivo de una boda o al tomar la toga viril ${ }^{16}$.

La rareza de este género de inscripciones en el norte de la Hispania citerior impide avanzar más en la determinación de estos extremos ${ }^{17}$. De cualquier forma en el sur de la Península son tres los tipos de liberalidades documentados de los que se beneficiaron también los incolae: sportulae ${ }^{18}$, epula ${ }^{19}$ y olea et balinea ${ }^{20}$. Cualquiera de ellas $-\mathrm{u}$ otra de las mencionadas - pudo ser la consignada en nuestro epígrafe -p. ej., [---epulo dat]o•sua•pecun[ia ---] encajaría bien ${ }^{21}$-, si bien al menos en la Bética parece más frecuente que los incolae se beneficiaran

to socioeconómico de la Bética: los epula», en Actas del I Coloquio de Historia Antigua de Andalucía. Córdoba, 1988, II, Córdoba, 1993, 73-88, espec. 74 nt. 9 sobre la terminología.

${ }^{15}$ Mangas 1971 (cit. nt. 10), 144; espec. 114 ss.; del Hoyo 1993 (cit. nt. 14), 86-87 a propósito de los epula, que considera una costumbre local particularmente arraigada en la Bética y zonas aledañas.

${ }^{16}$ Puede verse un amplio elenco de estas liberalidades y de sus motivaciones en ILS V pp. 908-912; cf. además Plin. ep. X 116, a propósito de Bitinia. En Italia las sportulae y distribuciones de alimentos - epula incluidos-están sobre todo vinculadas a la dedicatio de un monumento (como ocurre también en Hispania, cf. del Hoyo 1993, cit. nt. 14, 7679) o a la celebración del dies natalis; cf. Mrozek 1968 (cit. nt. 11), 156 ss. y 161 ss.

${ }^{17}$ Es llamativo que el único testimonio del norte de la Tarraconense, procedente de Aeso (Isona, Lérida), sea obra de una familia oriunda del Sur, en concreto de Oretum (c. Granátula, Ciudad Real; G. Alföldy, Römische Städtewesen auf der neukastilischen Hochebene, Heidelberg, 1987, 46 ss.) que dedicó una estatua ecuestre en honor de su hijo, muerto a los dieciocho años, datisque sportulis (CIL II 4465). Cf. G. Fabre, M. Mayer e I. Rodà, Inscriptions romaines de Catalogne. II. Lérida, Paris, 1985, núm. 35, subrayando el carácter excepcional del testimonio; en el mismo sentido, Le Roux 1994 (cit. nt. 5), 176-177.

${ }^{18}$ CIL II 1276 y 1282 (Siarum); 2011 y 5489 (Nescania).

${ }^{19}$ CIL II 2100 (Iliturgi = C. González Román y J. Mangas, Corpus de inscripciones latinas de Andalucía. III.1. Jaén, Sevilla, 1991, núm. 224 lám. 156); CIL II 5489 (Murgi), HAEp 1955-1956, 1027 (Naeua) y CIL II 1191.

${ }^{20}$ HEp 2, 1990, 469 (Singili).

${ }^{21} \mathrm{Cf}$. CIL II 2100, en la que el liberto Sexto Quintio Fortunato dedicó una estatua a Pólux, en cuyo pedestal rezaba: donum de | sua pecunia | dato epulo ciluibus et incolis et $\mid$ circensibus factis $\mid d d$. de una diuisio nummorum ${ }^{22}$ que del acceso a un epulum $^{23}$, mientras que, en lo que se refiere a olea et balinea, la información hispana se restringe a la interesantísima, pero por ahora única inscripción de Singili Barba ${ }^{24}$.

Respecto de la identidad del evergeta, dada la fragmentariedad del epígrafe, es Sergia・N[---] la única persona que podemos tomar en consideración, lo cual naturalmente no asegura su identificación. Su condición femenina no es en absoluto óbice para ello, pues un porcentaje no desdeñable de las liberalidades que tenemos comprobadas en Hispania fue obra de mujeres ${ }^{25}$.

3. En lo que respecta a la localización de Osicerda, resulta de particular importancia subrayar que este género de inscripciones relativas a liberalidades dirigidas al populus se colocaba generalmente en el centro urbano de la ciuitas $^{26}$, por lo que debe asumirse que el emplazamiento originario del epígrafe estaría en la misma ciudad de Osicerda. Por desgracia desconocemos el lugar exacto de aparición del fragmento, que pudo haber sido hallado en la misma localidad en la que se ha conservado o ser traído de otro lugar que, en cualquier caso, cabe presumir, no quedaría muy distante, por lo que la identificación de Osicerda en la misma Puebla de Híjar o en sus alrededores inmediatos - en los que no faltan noticias de restos antiguos ${ }^{27}$ - o bien en otro punto cercano del curso inferior del río Martín parece segura.

${ }^{22}$ Melchor 1994 (cit. nt. 11), 127: aparecen incolae en cuatro de los seis casos en los que se especifica los beneficiarios; en otros, a cambio, son excluidos: así, CIL II 13. No es el caso en África o Italia, en donde los principales beneficiarios son los decuriones y augustales; cf. R. Duncan-Jones, The Economy of the Roman Empire, Cambridge, 1974, 105106 y $188-200$.

${ }_{23}$ Del Hoyo 1993 (cit. nt. 14), 81-82: de la quincena de casos béticos en los que se especifica los beneficiarios de los epula, sólo en cuatro ocasiones aparecen los incolae entre ellos.

${ }^{24}$ HEp 2, 1990, 469; sobre la inscripción, además de la edición de E. Serrano y P. Rodríguez Oliva, «Tres nuevas inscripciones de Singilia Barba (El Castillón, Antequera, Málaga)», Baetica 11, 1988, 237-249, véase el excelente estudio de P. Le Roux, "Cité et culture municipale en Bétique sous Trajan», Ktéma 12, 1987, 271-284; también Le Roux 1994 (cit. nt. 5), 179-186. En ella los incolae son beneficiarios de las distribuciones, pero participan también en la colecta para erigir una estatua al mecenas: Ciues et incolae ex aere conlato... item populum uniuersum in municipio | habitantem et incolas oleo et balineo I gratuito dato...

${ }^{25}$ Entre ellas, algunas que afectaron a incolae: CIL 2011. Cf. Melchor, 1994 (cit. nt. 11), 123, 201 ss. De hecho, de los 38 epula béticos que recoge del Hoyo 1993 (cit. nt. 14), 7679 , espec. 81 , veinte fueron ofrecidos por mujeres.

${ }^{26}$ Melchor 1994 (cit. nt. 11), 189.

${ }^{27}$ P. Atrián, C. Escriche, J. Vicente y A. I. Herce, Carta arqueológica de España. Teruel, Teruel, 1980, 204-205 (= CATeruel). 
Esta ubicación resulta perfectamente coherente con la información disponible sobre Osicerda y no se aleja mucho de las defendidas tradicionalmente ${ }^{28}$. La más reiterada ha sido Osera (Zaragoza), localidad situada a unos $40 \mathrm{~km}$. al norte de La Puebla de Híjar, en la ribera izquierda del Ebro entre Velilla (Celsa) y Zaragoza ${ }^{29}$, que, a pesar de sustentarse tan sólo en la homofonía ha sido con frecuencia repetida e, incluso, cartografiada. Menos éxito tuvo la propuesta de Mosqueruela, en el Maestrazgo turolense, en donde existe un topónimo homónimo, seguramente de carácter erudito y moderno ${ }^{30}, \mathrm{o}$ la menos fundamentada aún de Cherta, cerca de Tortosa ${ }^{31}$. A mediados de siglo Bardavíu - según recoge Galiay - se inclinó por ubicarla en el Bajo Aragón, hacia Alcañiz, concretamente en Val de Vallerías ${ }^{32}$, y antes aún Masdeu proponía buscarla al Oeste de Alcañiz ${ }^{33}$, área hacia la que vienen apuntando algunos hallazgos monetales de la poco productiva ceca de usekerte / OSICERDA ${ }^{34}$, de los que se conocen ejemplares en colecciones de Alcañiz ${ }^{35}$ y un hallazgo en el Paso de la Guardia o la Ferradura, en el término mismo de La Puebla de Híjar ${ }^{36}$. El hallazgo del epígrafe que nos ocupa cir-

${ }^{28}$ Véanse las síntesis de G. Fatás, «De epigrafía cesaraugustana», en Symposion de ciudades augústeas II, Zaragoza, 1976, 106-107 y de A. Tovar, Iberische Landeskunde. 3. Tarraconensis, Baden-Baden, 1989, 408.

${ }^{29}$ Así, por ejemplo, V. J. de Lastanosa, Museo de las medallas desconocidas españolas, Huesca, 1645, 173, J. de Traggia, Aparato a la historia eclesiástica de Aragón, Madrid, 1792, t. II, 205-207 (que desdobla la ciudad en dos: Ossicerda que estaría en Singra y Ossigerda — siguiendo la grafía pliniana- que localiza en Osera) o J. A. Ceán, Sumario de las antigüedades romanas que hay en España, Madrid, 1832, 150, y tras ellos muchos autores modernos.

${ }^{30} \mathrm{Se}$ inclinaba por Mosqueruela, entre otros, P. Madoz, Diccionario histórico-geográfico-estadístico de España y sus posesiones de ultramar, Madrid, 1848, t. XII, 393; al respecto J. Lostal, Arqueología del Aragón romano, Zaragoza, 1980,116 . Hasta la fecha sólo hay constancia en esta localidad de hallazgos de la Edad del Bronce y de la primera Edad del Hierro, cf. CATeruel 191.

${ }^{31}$ F. Fita, BRAH 57, 1910, 321 nt. 1, que antes se inclinaba por Alcalá de Chivert, Castellón: así en BRAH 25, 1894, 284.

32 J. Galiay, La dominación romana en Aragón, Zaragoza, 1946, 72 haciéndose eco escuetamente de la propuesta. Ya antes Reichard dudaba entre Cherta e Híjar, apud Tovar 1989 , cit. nt. 28,408 .

${ }_{33}$ J. F. de Masdeu, Historia crítica de España..., Madrid, 1783-1805, t. 19, 311-313.

${ }^{34}$ También por el Bajo Aragón y desde una óptica numismática se inclina, tras haber tomado en consideración otras ubicaciones, A. Beltrán, «Las monedas hispano-latinas», III Congreso Nacional de Numismática, Numisma 147-149, 1978, 44 y nosotros mismos: M. y F. Beltrán Lloris, «Numismática hispanorromana de la Tarraconense», Numisma 162164, 1980, 69 nt. 1.

${ }^{35}$ MLH I.1, Wiesbaden, 1975, A.26; J. A. Benavente, Arqueología en Alcañiz, Zaragoza, 1987, 93.

${ }_{36}$ CATeruel 205. cunscribe la búsqueda a los alrededores de esta localidad, a la espera de identificar un yacimiento en la zona que responda a las características de un municipio romano.

4. Con las escasas noticias disponibles sólo puede realizarse un bosquejo de la trayectoria de la ciudad, que empieza a tomar cuerpo a partir de la segunda mitad del siglo I a. E. - con las emisiones bilingües- y se concreta, sobre todo, durante las dos primeras centurias del Principado ${ }^{37}$, una vez que Osicerda ha accedido a la condición municipal que documentan las emisiones locales acuñadas bajo Tiberio (MVN. OSICERDA), probablemente en época de Augusto, a juzgar por el pasaje en el que Plinio enumera a los Ossigerdenses (mss.) entre los Latini ueteres del convento cesaraugustano (III 24).

Si la carencia de noticias sobre la ciudad en los años de la conquista romana e inmediatamente posteriores así como la falta de acunaciones con leyendas indígenas son significativas, cabría concluir que Osicerda, ciudad sedetana según Ptolomeo (Ptol. II

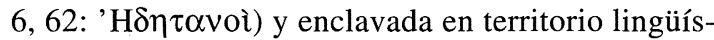
ticamente ibérico a juzgar por los epígrafes paleohispánicos bajoaragoneses ${ }^{38}$, no empezó a adquirir relevancia hasta una vez consolidado el proceso de provincialización.

Pese a su ascendencia ibérica, la ciudad muestra en el tránsito del siglo II al i a. E. un ambiente de mestizaje cultural y una notable apertura hacia su entorno o, al menos, esto parece deducirse del más antiguo testimonio disponible sobre ella, el ya famoso epígrafe ibérico de La Caridad de Caminreal ${ }^{39}$, que, pese a las dificultades de comprensión

${ }^{37}$ CIL II 4267 = RIT 341 y CIL II 4241 = RIT 325, datables a fines del siglo i y en el II d. E.

${ }^{38}$ MLH III.2, E.

${ }^{39}$ MLH III.2 E.7.1: likinete ekiar usekeŕteku. La última palabra se refiere obviamente a Osicerda, cuyo nombre se expresa en las monedas ibéricas en la forma usekerte, pero con la $r$ triangular $(\triangleleft=r)$, no con la romboidal $(\diamond=\hat{r}$; ) que figura en el letrero musivo. El último informe sobre las excavaciones en J. Vicente y B. Ezquerra, «X campaña de excavaciones arqueológicas en 'La Caridad' (Caminreal, Teruel)» en Arqueología aragonesa 1992, Zaragoza, 1994, 77-82 con la bibliografía fundamental, entre la que cabe destacar: J. Vicente y otros, «Las inscripciones de la casa de Likine (Caminreal, Teruel)», en J. Untermann y F. Villar (eds.), Lengua y cultura en la Hispania prerromana, $\mathrm{V} \mathrm{Co-}$ loquio de lenguas y culturas paleohispánicas, Salamanca, 1993, 747-772; «La Caridad (Caminreal, Teruel)», en La casa urbana hispanorromana, Zaragoza, 1991, 81-129; «El mosaico romano con inscripción ibérica de La Caridad (Caminreal, Teruel)», Actas de la mesa redonda hispanofrancesa sobre el mosaico romano en España, Madrid, 1989, 11-42. 
que plantea ${ }^{40}$, parece aludir a un osicerdense llamado likine, en el que se ha propuesto ver al propietario de la casa o, más verosímilmente, al de un taller musivo que actuaba en una amplia región del valle medio del Ebro ${ }^{41}$. Sea o no acertada esta explicación, el epígrafe resulta de extraordinario interés para comprender el ambiente en el que se desarrolla el proceso de romanización inicial en esta zona $\mathrm{y}$, sobre todo, establece una visión dinámica de las relaciones establecidas entre las comunidades de diferente cultura y lengua de la región, de la que hasta ahora apenas había indicios ${ }^{42}$, pues muestra a un individuo de nombre probablemente céltico ${ }^{43}$,

${ }^{40}$ Más bien acrecentadas que resueltas por el hallazgo, muy similar en fecha, texto y contexto, de Andelos (Muruzábal de Andión, Navarra): likine abulor'aune bilbiliar's'; al respecto, M. A. Mezquíriz, «Pavimento de «opus signinum» con inscripción ibérica en Andelos», Trabajos de Arqueología Navarra 10, 1991-1992, 365-367. Sobre estos dos epígrafes véanse los estados de la cuestión de J. Velaza, «Crónica epigráfica ibérica: hallazgos de inscripciones ibéricas en Levante, Cataluña, Aragón y Navarra (1989-1994)» en F. Villar y J. d'Encarnação, eds., La Hispania prerromana. Actas del VI Coloquio sobre lenguas y culturas prerromanas de la Península Ibérica (Coimbra 1994), Salamanca, 1996, 325-328 y L. Silgo, «Las inscripciones ibéricas de los mosaicos de Caminreal (Teruel) y Andelos (Navarra), en I. J. Adiego, J. Siles y J. Velaza, eds., Studia palaeohispanica et indogermanica J. Untermann..., Barcelona, 1993, 281-286, con la bibliografía fundamental.

${ }^{41}$ Ésta última es la propuesta de J. Untermann, «Comentarios a la inscripción musiva de Andelos», Trabajos de Arqueología Navarra 11, 1993-1994, 127-129, para quien likine tendría su taller central en Osicerda - desde donde actuó en Caminreal-y una delegación regida por Abulu en Bilbilis que trabajó en Andelos, combinando así la información de los dos epígrafes musivos.

${ }^{42} \mathrm{Al}$ respecto, F. Beltrán, «Romanización inicial en la Celtiberia: las inscripciones de Caminreal y Botorrita», Curso de verano de la Universidad de Vigo 1995, Xinzo de Limia, en prensa.

${ }^{43}$ Inicialmente likine fue entendido como una transcripción al ibérico del nombre latino Licinius -o, mejor, Licinus-; sin embargo la reiterada presencia en Botorrita 3 del antropónimo likinoś: (F. Beltrán, J. de $\mathrm{Hoz}$ y J. Untermann, El tercer bronce de Botorrita (Contrebia Belaisca), Zaragoza, en prensa, I 29 y 40; II 6 y 35; III 49; IV 36), nos inclina a considerarlo nombre céltico. Podría no ser éste el único elemento de raigambre céltica en la comarca, si el relieve de la estela del Palao (Alcañiz) que representa a un caído en el acto de ser devorado por buitres (F. Marco, «Nuevas estelas ibéricas de Alcañiz, Teruel», Pyrenae 12, 1976, 76 fig. 2) pudiera ser interpretado como una ilustración de la androfagia -en la que los vultúridos actúan como animales psicopompos- a la que aluden entre los pueblos celtas de Hispania Silio Itálico (Pun. III 340-343: «Venere et Celtae sociati nomen Hiberis. I His pugna cecidisse decus, corpusque cremari I tale nefas. Caelo credunt superisque referri, I impastus carpat si membra iacentia uultur»; XIII 470-471: «Tellure ut perhibent, is mos antiquus - Hibera I exanima obscoenus consumit corpora uultur») y Claudio Eliano (natur. anim. X 22 , referido a los vacceos), estudiada por F. Marco y, recientemente in extenso, por G. Sopeña, Ética y ritual. Aproximación al estudio de la religiosidad de los pueblos celtibéricos, Zaragoza, 1995, 210 ss. La interpretación del relieve, sin ser asentado en la ciudad sedetana de Osicerda, de lengua claramente ibérica, que es precisamente la utilizada tanto en el mosaico de la celtibérica Caminreal - los grafitos sobre cerámica recuperados en la casa son claramente célticos- cuanto en el de Andelos, ciudad enclavada en la parte del territorio de los vascones más abierta a los influjos célticos e ibéricos ${ }^{44}$, y todo ello expresado a través de pavimentos de técnica claramente romana y enclavados en casas de similar filiación material.

Algunos años después, a mediados del siglo I a. E., la ciudad acuña sus primeras monedas conocidas, con leyendas bilingües en ibérico y latín usekerte / OSI ${ }^{45}$, que abundan en lo dicho sobre la permeabilidad de la ciudad - en este caso desde la perspectiva de la latinización-, complementando lo que en el terreno de la cultura material implicaría la existencia en la ciudad de un taller regido por un indígena que elaborara pavimentos según la técnica romana del opus signinum. La cronología de estas emisiones descansa sobre todo en el análisis de los tipos, que copian claramente los de un par de denarios de época cesariana: el más evidente es el que representa a un elefante pisoteando un dragón o serpiente, sin duda una personificación de César triunfando sobre sus enemigos -en el exergo aparece la leyenda CAESAR - , pues su cognomen, según una explicación posiblemente falsa pero muy difundida (Serv. Aen. I 286), se originaría en el nombre de un elefante ${ }^{46}$. Crawford data esta emisión hacia 49-48 a. E., una vez que César se ha alzado en armas, y atribuye su producción a un taller móvil que acompañaría al general, que, no hay que olvidarlo, precisamente en el año 49 a. E. está operando en la región del Segre con motivo de la campaña de Ilerda, circunstancia que podría explicar la adopción de este tipo por la vecina ciudad de Osicerda. El motivo de la otra cara es una victoria alada caminando que sostiene una corona en alto y una palma sobre el hombro, de la que pueden señalarse diversos paralelos tardorrepublicanos, entre los que el más similar seguramente sea el correspondiente a las emisiones de Licinio Nerva de $47 \mathrm{o}$, menos probablemente, de 46 a. E. ${ }^{47}$.

segura, encuentra apoyo en otras manifestaciones iconográficas como la cerámica numantina o las estelas burgalesas y cántabras.

${ }^{44}$ Pero véanse las reservas de J. Velaza 1996 (cit. nt. 40), 327-328 a propósito de la lengua del epígrafe de Andelos. Sobre el ibérico como lengua vehicular, véase J. de Hoz, «La lengua y la escritura ibéricas, y las lenguas de los íberos», en Untermann y Villar (eds.), 1993 (cit. nt. 39), espec. 656 ss.

${ }^{45}$ Vives 1924 (cit. nt. 4), lám. 72; Villaronga 1994 (cit. nt. 4), 184.

${ }^{46}$ I. Kajanto, The Latin Cognomina, Helsinki, 1965, 42.

${ }^{47}$ M. Crawford, Roman Republican Coinage, Cambridge, 1974,89 y 92 , y núms. 443 y 454-3/4. 
No debe perderse de vista que, apenas a una veintena de kilómetros de La Puebla de Híjar, en la antigua Celse (Velilla de Ebro) — ciudad que, por cierto, también acuñó moneda bilingüe ${ }^{48}$-, Marco Emilio Lépido, seguramente cumpliendo designios de César, estableció hacia el año 44 a. E. la primera colonia romana del valle medio del Ebro, cuyo nombre, Victrix Iulia Lepida (Celsa), claramente alusivo a la victoria y a César, incide onomásticamente en los mismos tópicos que refleja en imágenes la iconografía de las monedas osicerdenses.

Así pues, en estas fechas Osicerda junto con $\mathrm{Cel}$ sa e Ilerda - cuya temprana latinización onomástica demuestra el bronce de Ascoli ${ }^{49}$ - parecen constituir la cuña más avanzada del proceso de romanización en estas tierras ibéricas del interior antes de que Augusto, con la fundación de Caesaraugusta, desplazara hacia el Oeste el centro de gravedad de la región ${ }^{50}$. La precoz latinización y el procesarianismo que las emisiones bilingües de los Osicerdenses parecen documentar, podrían explicar la pronta promoción a la condición de Latini ueteres que Plinio documenta (NH III 24) y que, pese a escribir el naturalista en época de Vespasiano, hay que datar con anterioridad -Plinio obviamente los llama 'latinos viejos' para distinguirlos de los que se beneficiaron de la medida del príncipe flavio (NH III 30)_, probablemente en tiempos de Augusto, fecha de la que data la mayor parte de la información que Plinio utiliza y con la que concuerda el tendido de una calzada a lo largo de la ribera derecha del Ebro documentada por un miliario augusteo recientemente aparecido en Jatiel, a $5 \mathrm{~km}$ de La Puebla de Híjar ${ }^{51}$. Bajo Tiberio la ciudad es con seguridad municipium según confirma una corta emisión de ases y sémises con el busto de este emperador y el toro estante - motivo utilizado también por la vecina ceca de Celsa y por varias otras del valle medio del

\footnotetext{
${ }^{48}$ Vives 1924 (cit. nt. 4), lám. 72.

${ }^{49} \mathrm{CIL} \mathrm{I}^{2}$ 709: como tantas veces se ha subrayado, los tres jinetes ilerdenses son los únicos de la turma Salluitana que exhiben praenomina y nomina romanos.

${ }^{50} \mathrm{Al}$ respecto, F. Beltrán, «Caesar Augusta, ciudad de Augusto», Caesaraugusta 69, 1992, 37 ss.

${ }_{51}$ F. Beltrán, Kalathos, en prensa.
}

Ebro- y la mencionada leyenda MVN. OSIC u OSICERDA $^{52}$.

Por último y dejando ahora al margen el testimonio de Ptolomeo (II 6, 62), hay que mencionar los dos documentos epigráficos relativos a osicerdenses hallados en Tarraco, cuya fecha es más o menos coetánea de la inscripción de La Puebla de Híjar. La primera, datable bajo los Flavios o a comienzos del siglo II, está dedicada por Emilia Cara a su marido, Lucio Cornelio Romano - de la tribu Galeria como corresponde a una fundación augustea-, que fue sacerdote del culto imperial y dunvir en su ciudad y, después, emigró a Tarraco, en donde alcanzó también el dunvirato: L•Cornelio | C•f•Gal | Romano I flamini•П uir | Osicerd•et | П uir coloniae | Tarraconens I Aemilia Kara I uxor ${ }^{53}$. La otra la colocó Lucio Numisio Montano, un eques de Tarraco promocionado a dicho rango por Adriano, en honor de su mujer: Porciae M॰f I Maternae |

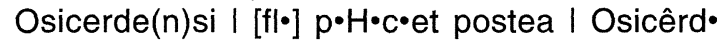
Câesar[aug] | Tarrac•pêrpêtuâe | L・ Numisius | Montanus | uxori ${ }^{54}$. Todas estas familias, Porcii, Cornelii y Aemilii - suponiendo que Emilia Cara fuera osicerdense- están bien documentadas en la comarca bajoaragonesa: los Porcii, en un posible gran monumento funerario de La Dehesa de Baños, cerca de Chiprana ${ }^{55}$ y en un altar funerario de Alcañiz dado a conocer por Bardavíu y Thouvenot en $1930^{56}$; los Aemilii, en el impresionante mausoleo de la partida de Las Suertes, en Fabara, erigido en honor de Lucio Emilio Lupo ${ }^{57}$; y los Cornelii, en un epitafio relativo a una Cornelia L. f. Sir[.]steiun, de cognombre ibérico, editado recientemente ${ }^{58}$. Los dos epígrafes de Tarragona resultan un indicador muy valioso sobre la promoción social y política de las familias dirigentes del municipio, como se ha visto bien implantadas en la comarca, y con proyección tanto hacia la capital conventual, Caesaraugusta, como hacia la provincial, Tarraco.

${ }^{52}$ Vives 1924 (cit. nt. 4), lám. 159; Ripollès 1992 (cit. nt. 4), 142, núms. 468-469.

${ }^{53}$ CIL II $4267=$ RIT 341.

${ }^{54}$ CIL II 4241 = RIT 325; cf. CIL II 4231 = RIT 295; CIL II $4275=$ RIT 349.

${ }^{55} \mathrm{G}$. Fatás y M. Martín Bueno, Epigrafía romana de $\mathrm{Za}$ ragoza y su provincia, Zaragoza, 1977, núm. 17.

${ }_{56} \mathrm{~V}$. Bardavíu y R. Thouvenot, «Fouilles dans la région de Alcañiz (Province de Teruel)», Publications de la Bibliothèque de l'École des Hautes Études Hispaniques, 11, 2, Bordeaux, 1930, 9-32.

${ }^{57}$ CIL II 5851; A. Blanco, El puente de Alcántara en su contexto histórico, Madrid, 1977, 72-75.

${ }^{58} \mathrm{M}$. Navarro, La epigrafía romana de Teruel, Teruel, 1994, núm. 5. 